OPEN ACCESS

Edited by:

Masaaki Murakami,

Hokkaido University, Japan

Reviewed by:

Hideki Ogura,

Yale University, USA

Gaurav K. Gupta,

Harvard Medical School, USA

Hidemitsu Kitamura,

Hokkaido University, Japan

*Correspondence:

Caroline Blackwell,

Information Based Medicine, Hunter Medical Research Institute, New Lambton, NSW 2305, Australia caroline.blackwell@newcastle.edu.au

Specialty section: This article was submitted to Inflammation, a section of the journal Frontiers in Immunology

Received: 26 February 2015 Accepted: 07 May 2015

Published: 09 June 2015

Citation:

Blackwell C (2015) The role of infection and inflammation in stillbirths: parallels with SIDS?

Front. Immunol. 6:248.

doi: 10.3389/fimmu.2015.00248

\section{The role of infection and inflammation in stillbirths: parallels with SIDS?}

\author{
Caroline Blackwell ${ }^{1,2 *}$ \\ ${ }^{1}$ School of Biomedical Sciences, Faculty of Health and Medicine, University of Newcastle, Newcastle, NSW, Australia, \\ ${ }^{2}$ Information Based Medicine, Hunter Medical Research Institute, New Lambton, NSW, Australia
}

It has been suggested that stillbirths are part of the spectrum of infant deaths that includes sudden infant death syndrome (SIDS). This paper examines the hypothesis that risk factors associated with stillbirths might contribute to dysregulation of inflammatory responses to infections that could trigger the physiological responses leading to fetal loss. These include genetic factors (ethnic group, sex), environmental (infection, cigarette smoke, obesity), and developmental (testosterone levels) factors. Interactions between the genetic, environmental, and developmental risk factors are also considered, e.g., the excess of male stillborn infants in relation to the effects of testosterone levels during development on pro-inflammatory responses. In contrast to SIDS, inflammatory responses of both mother and fetus need to be considered. Approaches for examining the hypothesis are proposed.

Keywords: stillbirth, sudden infant death syndrome, inflammation, infection, cigarette smoke, ethnicity, obesity

\section{Infection and Inflammation in Infant Deaths}

There have been suggestions that stillbirths are part of the spectrum of infant deaths associated with sudden infant death syndrome (SIDS) based on epidemiological parallels (1). Some of the reported parallels included: ethnic background; maternal smoking; small for gestational age infants; evidence of infection/inflammation in mother and/or fetus. Infections have been implicated in the etiology of stillbirths in both developing and industrialized countries (2-4). As with SIDS and sudden unexpected deaths in infancy (SUDI), no single organism has been implicated (5-7). The common thread to be considered in this review is the inflammatory responses to infection and how the risk factors identified in epidemiological studies might affect these responses in both mother and infant. Based on our previous work on SIDS, our hypothesis is that genetic and environmental risk factors that result in dysregulation of inflammatory responses by mother and/or infant to infection could contribute to events leading to some unexplained stillbirths. Table 1 lists the major risk factors for SIDS and for stillbirths and cites the supporting literature. In the following sections, the effects of genetic and environmental factors on inflammatory responses will be assessed.

\section{Infection in Stillbirths}

The incidence of stillbirths ranges from as few as $3 / 1000$ births in developed countries to as many as 45/1000 in developing countries (25) where infection is more common.

Early studies implicated inflammation associated with infectious agents $(26,27)$. There are usually no overt signs of infection prior to fetal loss including: maternal fever or chills; abdominal discomfort; or fetal tachycardia. Ascending bacterial infection (before and after membrane rupture) 
TABLE 1 | Comparison of risk factors for SIDS/SUDI and stillbirths

\begin{tabular}{llll}
\hline SIDS/SUDI & Reference & Stillbirths & Reference \\
\hline Ethnic group & $(8-10)$ & Ethnic group & $(11-13)$ \\
Male gender & $(14,15)$ & Male gender & $(16,17)$ \\
Cigarette smoke & $(18)$ & Cigarette smoke & $(12)$ \\
Infection & $(5,19)$ & Infection & $(3,4)$ \\
Prematurity & $(20)$ & Prematurity & $(12)$ \\
Small baby & $(20)$ & Small baby & $(12)$ \\
$\begin{array}{l}\text { Overweight/maternal } \\
\text { obesity }\end{array}$ & $(21,22)$ & Overweight/maternal & $(23,24)$ \\
\end{tabular}

was identified as the most common infectious cause of stillbirth. Infection can also occur from hematogenous spread (4). The most common organisms involved were Escherichia coli, group B Streptococcus pyogenes, and Ureaplasma urealyticum. The two most common viral infections associated with stillbirths were parvovirus and Coxsackie virus $(3,26)$. A more recent study identified cytomegalovirus (CMV) in $15 \%$ of stillbirths (28). Serological studies have implicated Chlamydia trachomatis in a Scandinavian study of stillbirths (29). Although infection is considered a common cause of stillbirth, it is often hard to attribute this causally for a number of reasons. Several groups have studied the use of polymerase chain reaction (PCR) to identify specific viral and bacterial DNA and RNA and have found it to be more sensitive than routine microbiological methods in detecting evidence of infection in stillborn babies $(28,30)$.

Both invasive and toxigenic bacteria need to be considered as bacterial exotoxins or their cellular components can act as superantigens eliciting strong pro-inflammatory responses. A comprehensive review of the literature relating to stillbirth/intrauterine fetal death (IUFD) and infection suggested that between 10 and $25 \%$ of all cases of IUFD in developed countries were associated with infection (4). We identified pyrogenic toxins of Staphylococcus aureus in serum or tissues of over $50 \%$ of SIDS infants from five different countries (31) and toxins of enteric organisms have also been implicated (32); however, there has been no systematic assessment of material from stillbirths for presence of bacterial toxins.

The mechanisms proposed for the role of infection in stillbirths include (1) maternal illness resulting in fever, respiratory distress, or systemic responses to the infection; (2) infection of the placenta resulting in reduced fetoplacental blood flow; (3) direct infection of the fetus; (4) induction of pre-term labor (4). Inflammation might contribute to all of these, and the inflammatory response of the fetus also needs to be considered.

\section{Inflammation and Infant Deaths}

The inflammatory response is the major protective mechanism evolved to deal with pathogenic micro-organisms. The proinflammatory cytokines are involved in clearing the microorganism. The anti-inflammatory cytokines are involved in damping down the pro-inflammatory responses to prevent collateral damage of a too abundant response to infection; however, an innate tendency to enhanced anti-inflammatory signaling is thought to increase the risk of death through infection. Successful reproduction necessitates adequate immune tolerance to allow pregnancy to proceed without rejecting the fetus, half of whose antigens are from the father. Pro-inflammatory responses have been associated with increased resistance to infection and antiinflammatory responses with increased fertility (33). Genetic and environmental factors that disturb the balance between pro- and anti-inflammatory cytokines might result in fetal damage. There is evidence that some ethnic groups at increased risk of infant deaths due to infection, SIDS or stillbirths $(12,23,34)$. These include Indigenous communities in Canada and Australia and African-Americans $(13,23,34)$. In these populations at higher risk of stillbirths, there is a general genetic predisposition to strong pro-inflammatory responses (35-40).

Women with low capacity to respond to vaginal infection through the production of pro-inflammatory cytokines, interleukin (IL)-1 $\beta$, IL-6, and IL-8 might have a more permissive environment for pathogens to flourish and be at risk of ascending uterine infection and chorioamnionitis (41). Enhanced pro-inflammatory responses to vaginal infection or periodontal disease (42) are suggested to be detrimental to pregnancy and elevated levels of IL- 6 have been found to be a predictor of pre-term labor $(43,44)$.

As with SIDS, histopathological changes in the placenta or fetus are not always consistent (45), and the presence of organisms does not always imply causation, although it is more likely if micro-organisms are found in fetal tissue compared with placenta or fetal membranes. Examination of placentas from live and stillborn infants found evidence of inflammation in $30.4 \%$ of stillbirths compared with $12 \%$ of controls. Inflammation was more common in placentas from early stillborn deliveries and also in early live births (46). Chorioamnionitis without fetal inflammatory responses was associated with stillbirth in early pre-term pregnancies (47).

It has been recommended that there is a need to assess the molecular evidence for inflammation in these deaths (48). In the case of SIDS, factors affecting the inflammatory responses of the infant need to be considered; for stillbirths, factors affecting the inflammatory responses of both mother and infant need to be considered. The methodology is available and preliminary studies on levels of cytokines in matched samples of maternal plasma, cord blood, and amniotic fluid from late pregnancy are reported in this issue (49). The levels of pro-inflammatory cytokines are significantly higher in the amniotic fluid compared with the levels in cord blood or maternal plasma (Figure 1).

\section{Assessment of Inflammatory Responses in Relation to Risk Factors}

\section{Ethnic Group}

The incidences of infant mortality due to infection, SIDS and stillbirths are higher among families of Indigenous groups (e.g., Aboriginal Australians and Native Americans) compared to families of European origins in the same countries (Table 2).

Ethnicity was a significant risk for stillbirth in the United Kingdom; those groups at increased risk included African, AfroCaribbean, Indian, and Pakistani mothers. In other countries, Indigenous mothers have an increased risk for stillbirth. While these disparities have been ascribed primarily to socio-economic disadvantage, there is emerging evidence that genetic background 


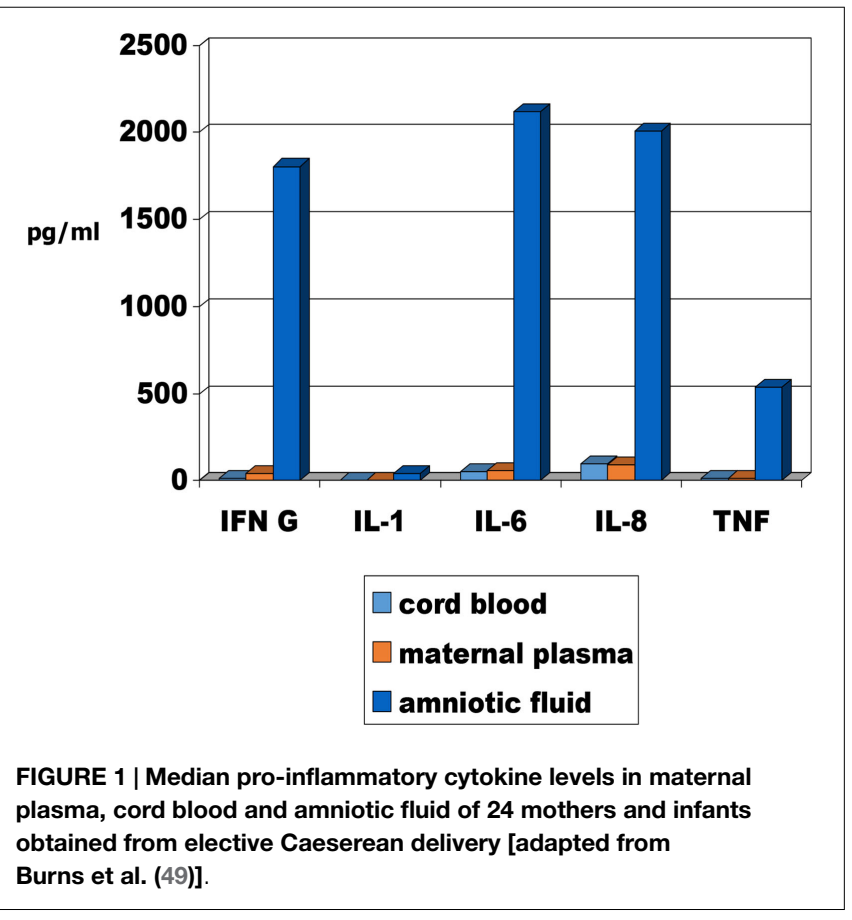

TABLE 2 | Incidence of stillbirths among different ethnic groups.

\begin{tabular}{lc}
\hline Country & No/1000 births \\
\hline United kingdom (12) & 3.2 \\
European & 4.0 \\
Non-UK & 7.4 \\
African & 6.7 \\
Afro-Caribbean & 4.2 \\
Bangladeshi & \\
Indian & 3.9 \\
UK & 6.4 \\
$\quad$ Non-UK & \\
Pakistani & 4.1 \\
UK & 6.9 \\
Non-UK & \\
Australia (11) & 5.9 \\
Non-Indigenous & 9.1 \\
Indigenous & \\
United states (13) & 5.44 \\
Hispanic & 4.75 \\
Non-Hispanic white & 11.13 \\
Non-Hispanic black & 6.17 \\
Native American/Alaska Native & \\
\hline
\end{tabular}

(40) and interactions between environmental factors such as cigarette smoke might contribute to susceptibility to, and severity of, inflammatory responses to infections $(37,50)$.

In relation to potential underlying factors affecting inflammatory responses and their role in stillbirths, it is important to note that cytokine gene polymorphisms associated with high-level responses of pro-inflammatory cytokines or low-level responses of anti-inflammatory cytokines such as IL-10 are predominant among some Indigenous groups, South Asians, and American Black populations $(36,40,51)$. There are experimental and epidemiological studies indicating that genetic polymorphisms in the inflammatory response might contribute to poor pregnancy outcome; however, the results are inconsistent. Pre-term labor enhances the risk of stillbirth (4). Important risk factors include intrauterine infection/inflammation and social factors (stress, smoking, heavy work). The final common pathway appears to be activation of the inflammatory cascade. Bacterial infection and/or inflammation of the choriodecidual interface induces proinflammatory cytokine responses leading to neutrophil activation, synthesis, and release of prostaglandins causing uterine contractions and metalloproteinases weakening fetal membranes (52). Polymorphisms associated with increased production of proinflammatory and/or decreased production of anti-inflammatory cytokines have been implicated in pre-term birth. Those enhancing the magnitude or duration of the responses were associated with risk of pre-term birth $(53,54)$. In vitro studies with leukocytes from women with recurrent pregnancy loss found significantly higher levels of interferon- $\gamma($ IFN- $\gamma$ ) and a trend toward increased TNF- $\alpha$ production compared with women with no history of pregnancy loss. In relation to IL- 6 and TGF- $\beta$, no significant differences were detected between the groups (55).

\section{Modifiable Risk Factors and Inflammation}

In relation to our previous studies on interactions between genetic and environmental factors on inflammatory responses, it is recommended that assessments of the genetic predisposition to inflammation need to control for environmental risk factors that alter cytokine responses to infection or toxins $(37,39)$. The major environmental factors to be considered in this review are coinfections, smoking, and obesity.

\section{Infections}

Virus pandemics have been associated with increased risk of preterm labor and fetal loss $(56,57)$. There are a number of models that indicate that virus infections can potentiate the effects of bacterial toxins implicated in SIDS (58-60). There is also a mouse model that found that while an asymptomatic infection with the murine gamma herpes virus 68 did not disrupt pregnancy outcome, the infection could upregulate the pro-inflammatory responses to small quantities of endotoxin in both placenta and decidua, resulting in pre-term labor and fetal loss. Similar responses were observed for human primary trophoblast and trophoblast cell lines infected with this virus prior to exposure to endotoxin (61). The enhancement of pro-inflammatory responses to endotoxin was attributed to priming by IFN- $\gamma$ and TNF- $\alpha$ responses to the virus infection. Additional evidence for the role of IFN- $\gamma$ was provided by in vitro studies with human monocytic cells and the THP-1 cell line $(50,62)$ (Moscovis et al., this issue).

Chronic infections such as Helicobacter pylori, Chlamydia pneumoniae, and CMV can also significantly increase proinflammatory markers (63). H. pylori infection is significantly higher among mothers with small for gestational age infants (64). In a population in India, periodontal disease was associated with increased levels of C-reactive protein (CRP) and also with preterm birth (65).

\section{Cigarette Smoke}

Both active smoking and passive exposure to cigarette smoke have been reported to enhance risk of stillbirth (12). Cigarette 
smoke can influence infection and inflammation is several ways: (1) enhanced susceptibility to respiratory virus infection and subsequent enhanced colonization by potential bacterial pathogens; (2) increase in the numbers and species of respiratory bacteria due to enhanced "stickiness" of epithelial cells coated with smoke components (66); (3) enhanced pro-inflammatory responses to bacterial antigens (50); (4) reduction in anti-inflammatory IL-10 responses (37).

IL-10 appears to protect the fetus against pathogens. IL-10 knockout mice are at greater risk of some pregnancy pathologies that occur in response to infection. Low doses of endotoxin given to IL-10 knockout mice can cause fetal resorption in early pregnancy (67) and pre-term labor in late pregnancy (68). No effect on pregnancy was observed when wild-type mice were given the same dose. IL-10 acts through inhibition of inflammatory cytokines including TNF $\alpha$, IFN- $\gamma$, and IL-6 $(67,69)$.

The IL10-1082A alleles have been associated with reduced production of IL-10. One SNP (G-1082A) in the promoter sequence of the IL10 gene associated with under-expression of plasma IL10 levels $(70,71)$ was present in a significantly greater proportion of ethnic groups at increased risk of stillbirths: Black Americans (45\%) (36), Bangladeshis (84\%), and Aboriginal Australians (83\%) compared with Caucasian populations (31\%) (40). Smokers had significantly lower baseline levels of IL-10 and lower responses to endotoxin than non-smokers (37). When assessed by genotype, the differences between smokers and non-smokers were significant for individuals with the heterozygous variant (GA) and the variant (AA). These data suggest interactions between cigarette smoke and genetic factors that result in reduced control of pro-inflammatory responses by IL-10.

\section{Obesity}

One of the latest meta-analyses of risk factors for stillbirths indicated that maternal overweight/obesity [body mass index (BMI) $>25 \mathrm{~kg} / \mathrm{m}^{2}$ ] was the highest modifiable risk factor with a population attributable risk (PAR) of $8-18 \%$ contributing to $>8000$ stillbirths across all high-income countries. Maternal smoking had a PAR of $4-7 \%$ contributing to more than 2800 stillbirths across all high-income countries (23). The physiological mechanisms contributing to stillbirths are not well defined; however, obesity increases the risk of gestational diabetes and hypertension. There is evidence to suggest inflammation is also involved.

Adipose tissue from lean individuals preferentially secretes anti-inflammatory adipokines such as adiponectin, transforming growth factor beta (TGF $\beta$ ), IL-10, IL-4, IL-13, IL-1 receptor antagonist (IL-1Ra), and apelin. By contrast, obese adipose tissue mainly releases pro-inflammatory cytokines among which are TNF- $\alpha$, IL-6, leptin, visfatin, resistin, angiotensin II, and plasminogen activator inhibitor 1 (72). In studies of obesity among Indigenous groups in which the genotype associated with higher levels of IL-6 responses is predominant, levels of this cytokine were associated with higher BMI $(73,74)$. Using CRP as a marker for inflammation, there is a positive correlation between BMI and CRP among adults (75). In our current studies, BMI correlated with CRP levels among Indigenous Australian women during pregnancy (Pringle, this issue).

\section{Fetal Growth Restriction}

Fetal growth restriction had the largest PAR for stillbirths in a major study of still birth risk factors in the United Kingdom (12). Down regulation of IL-10 in the placenta has been associated with IUGR in studies of a Caucasian (Swedish) (76) and an Asian (Pakistani) (77) population. Elevated CRP $\left(\geq 25 \mathrm{mg} \mathrm{L}^{-1}\right)$ was associated with lower estimated fetal weight in the third trimester and lower weight at birth and an increased risk of a small for gestational age infant (78). In a mouse model, IL-10-reduced endotoxin-induced growth retardation and fetal deaths (79); and we have found a significant correlation $(r=0.91)$ between levels of maternal and cord blood IL-10 among matched samples from elective Caesarian deliveries (49).

Both human recombinant IL-10 and the CMV IL-10 analog down regulate matrix metalloprotein 9 (MMP 9) involved in implantation. Reduced MMP 9 activity in early placenta formation has been suggested to affect cytotrophoblast remodeling of the uterine vasculature and restrict fetal growth (80). There have been no prospective studies on presence of the levels of IL-10 or the presence of CMV IL-10 analog in human pregnancy outcome. It needs to be determined if these might be associated with lowbirth weight or small for gestational age infants if there is a parallel with the mouse models. The report that $15 \%$ of stillbirths in one series had evidence of CMV infection warrants further studies into the role of these infections in relation to infection and inflammation on the outcome of pregnancy, fetal survival, and health (28).

There is evidence from animal models that elevated testosterone during pregnancy results in intrauterine growth retardation (81). Among women with polycystic ovary (PCO) syndrome, maternal androgens are increased during pregnancy. At 10-16 weeks, the PCO group had higher levels of testosterone and the differences were significant at 22-28 weeks (82). In the PCO mothers, there was a higher proportion of small for gestational age infants $(12.8 \%)$ compared with the control group (2.8\%); and the SGA infants of the mothers with PCO were significantly smaller (83). Higher levels of testosterone during pregnancy at 17 and 33 weeks were associated with lower birth weight and length of the infant. The levels ranged from 0.5 to $7.2 \mathrm{nMol} \mathrm{L}^{-1}$ at 13 weeks and from 0.9 to $14.5 \mathrm{nMol} \mathrm{L}^{-1}$ at 33 weeks (84). If inflammatory responses are contributing to growth restrictions, the effects of testosterone need to be considered in the context of inflammation (62).

\section{The Male Excess in Stillbirths}

For both SIDS and stillbirths, there is a male excess. In an early analysis of the sex ratio, the authors analyzed stillbirths in the United States from 1922 to 1936. The proportion of males at $<16$ weeks was nearly $80 \%$ but fell to $67 \%$ at 16 weeks, a low of $53.5 \%$ at 28 weeks but rose to $57 \%$ by $36-40$ weeks (16) (Figure 2). In a recently reported analysis of birth outcomes in Canada between 2002 and 2007, 54.8\% of males were stillborn compared to $51.4 \%$ of live births (17). The greatest difference between males and females appeared to between 20 and 24 weeks gestation as noted in the earlier study. 

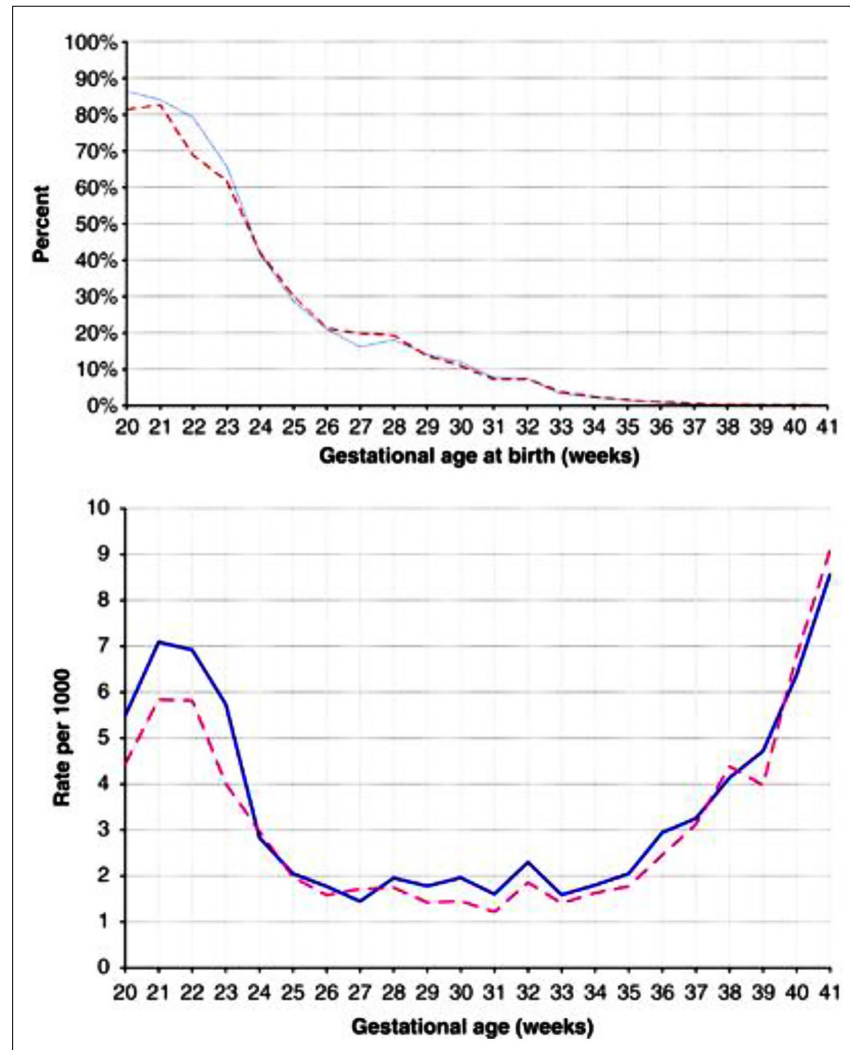

FIGURE 2 | (A) Percentage of singleton stillbirths among all singleton livebirths and stillbirths (prevalence approach). Data are for males (solid blue line) and females (dashed red line), presented by gestational age. (B) Number of stillbirths per 1000 singleton livebirths and stillbirths combined (incidence approach). Data are for males (solid blue lines) and female (dashed red lines), presented by gestational age. Reproduced with permission (17).

There is a rise in testosterone production associated with the period during which SIDS is most prevalent. Between 1 and 5 months, testosterone levels range from 0.03 to $6.14 \mathrm{nMol} \mathrm{L}^{-1}$ for males and 0.03 to 0.17 for females. In males, these levels decrease to $0.07-0.24$ at $6-11$ months. The ranges of testosterone in the adult females $\left(<0.4\right.$ to $\left.3.1 \mathrm{nMol} \mathrm{L}^{-1}\right)$ tested in our studies were within the range for males in the 1 - to 5 -month age range. There was a positive correlation between testosterone levels and pro-inflammatory responses to LPS when the cells were pre-treated with IFN- $\gamma$ or IFN- $\gamma$ and a water soluble cigarette smoke extract (62).

Fetal plasma testosterone levels for males were significantly higher (range 1.7-2.9 $\mathrm{nMol} \mathrm{L}^{-1}$ ) than levels for females (range 0.45-1.3 nMol L ${ }^{-1}$ ) (85) (Figure 3). If testosterone has a similar effect on inflammatory responses in the fetus, male infants might have significantly higher pro-inflammatory responses to infection or bacterial components. We found many of the pro-inflammatory cytokines are higher in the amniotic fluid of males and the antiinflammatory IL-1Ra significantly higher in females (Table 3).

During the 20- to 24-week period when the difference between male and female stillbirths is most obvious, the difference in fetal testosterone levels is greatest. The testosterone levels rise significantly with gestational age among females but remain steady among males (Figure 3) (85). This raises the hypothesis that the higher testosterone levels present in males at 20-24 weeks

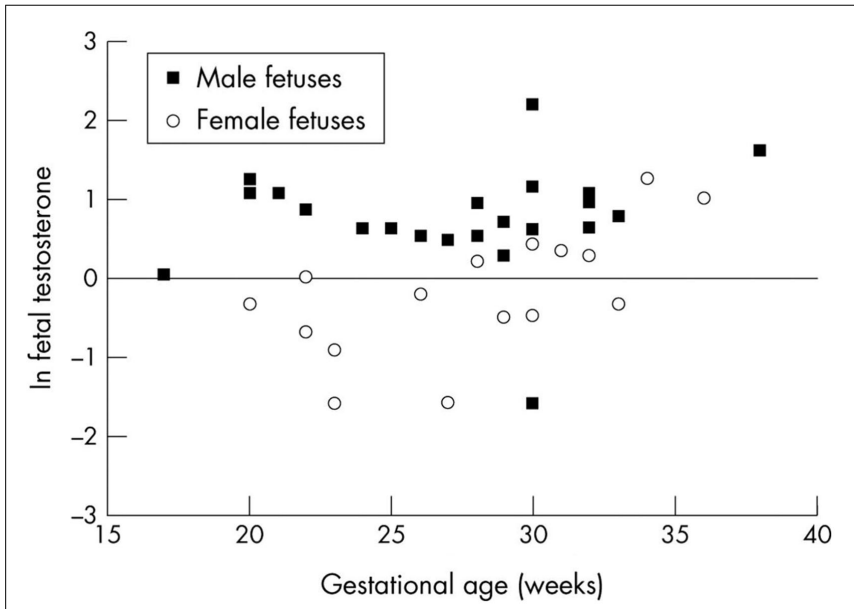

FIGURE 3 | Fetal testosterone levels, sex and gestational age

TABLE 3 | Medians and ranges of cytokine levels $(\mathrm{pg} / \mathrm{ml})$ in amniotic fluid of male and female infants.

\begin{tabular}{lllll}
\hline Cytokine & Female $(\boldsymbol{n}=\mathbf{1 2})$ & Range & Male $(\boldsymbol{n}=\mathbf{1 2})$ & Range \\
\hline IFN- $\gamma$ & 1373 & $15-6270$ & 2717 & $96-14,417$ \\
IL1- $\beta$ & 28 & $<2.4-68$ & 41 & $<2.4-121$ \\
IL-6 & 2270 & $292-10,738$ & 1218 & $398-12,928$ \\
IL-8 & 1794 & $578-4185$ & 2402 & $621-9179$ \\
TNF- $\alpha$ & 351 & $311-2025$ & 733 & $24-3176$ \\
IL-10 & 56 & $9-226$ & 112 & $<1.8-303$ \\
IL1-Ra* & 3908 & $1786-6295$ & 1839 & $330-5064$ \\
\hline
\end{tabular}

$* P<0.001$

gestation enhance pro-inflammatory responses as noted in our in vitro studies (62) and partly explain the excess of male stillbirths in this age range (Figure 2). Experimental systems are available to assess these interactions.

\section{Conclusion}

There is evidence from a variety of sources to suggest infection and inflammation might play a role in fetal deaths. As a variety of micro-organisms has been identified in studies of stillbirths, the common thread is most likely the effects of the inflammatory responses to infection. There is evidence to support the hypothesis that risk factors associated with stillbirths could contribute to dysregulation of the balance of inflammatory responses to infection, and these responses might trigger physiological interactions leading to fetal loss. The following recommendations are derived from the assessment of how dysregulation of the inflammatory responses could help explain the risk factors associated with stillbirths.

1. Samples from both mother and infant need to be assessed by both conventional diagnostic methods and new molecular methods for evidence of infectious agents, particularly combinations of virus and bacteria.

2. Samples from both mother and infant need to be assessed for presence of bacterial toxins, both soluble and cellular, that can act as superantigens that can induce powerful cytokine responses. 
3. Direct assessment of material from both mother and infant for evidence of pro-inflammatory and anti-inflammatory cytokines is needed.

4. Determination of cotinine levels in body fluids would help determine the level of exposure to cigarette smoke.

5. For both mother and infant, determine cytokine gene polymorphisms associated with high- or low-inflammatory responses and implicated in pre-term birth.

6. Experimental studies to assess further the interactions between genetic, developmental, and environmental risk

\section{References}

1. Walsh S, Mortimer G. Unexplained stillbirths and sudden infant death syndrome. Med Hypotheses (1995) 45(1):73-5. doi:10.1016/0306-9877(95)90206-6

2. Tolockiene E, Morsing E, Holst E, Herbst A, Ljungh Å, Svenningsen N, et al. Intrauterine infection may be a major cause of stillbirth in Sweden. Acta Obstet Gynecol Scand (2001) 80(6):511-8. doi:10.1034/j.1600-0412.2001.080006511.x

3. Goldenberg RL, Thompson C. The infectious origins of stillbirth. Am J Obstet Gynecol (2003) 189(3):861-73. doi:10.1067/S0002-9378(03)00470-8

4. McClure EM, Goldenberg RL. Infection and stillbirth. Semin Fetal Neonatal Med (2009) 14(4):182-9. doi:10.1016/j.siny.2009.02.003

5. Blackwell CC, Moscovis SM, Gordon AE, Al Madani AM, Hall ST, Gleeson M, et al. Cytokine responses and sudden infant death syndrome: genetic, developmental, and environmental risk factors. J Leukoc Biol (2005) 78:1242-54. doi: $10.1189 /$ jlb.0505253

6. Goldwater PN. Sterile site infection at autopsy in sudden unexpected deaths in infancy. Arch Dis Child (2009) 94(4):303-7. doi:10.1136/adc.2007.135939

7. Weber MA, Klein NJ, Hartley JC, Lock PE, Malone M, Sebire NJ. Infection and sudden unexpected death in infancy: a systematic retrospective case review. Lancet (2008) 371(9627):1848-53. doi:10.1016/S0140-6736(08)60798-9

8. Adams MM. The descriptive epidemiology of sudden infant deaths among natives and whites in Alaska. Am J Epidemiol (1985) 122(4):637-43.

9. Alessandri LM, Read AW, Stanley FJ, Burton PR, Dawes VP. Sudden infant death syndrome in aboriginal and non-aboriginal infants. J Paediatr Child Health (1994) 30(3):234-41. doi:10.1111/j.1440-1754.1994.tb00626.x

10. Balarajan R, Soni Raleigh V, Botting B. Sudden infant death syndrome and postneonatal mortality in immigrants in England and Wales. BMJ (1989) 298(6675):716-20. doi:10.1136/bmj.298.6675.716

11. Alessandri LM, Stanley FJ, Waddell VP, Newnham J. Stillbirths in Western Australia 1980-1983: influence of race, residence and place of birth. Aust N Z J Obstet Gynaecol (1988) 28(4):284-92. doi:10.1111/j.1479-828X.1988.tb01684.x

12. Gardosi J, Madurasinghe V, Williams M, Malik A, Francis A. Maternal and fetal risk factors for stillbirth: population based study. BMJ (2013) 15:346. doi: $10.1136 /$ bmj.f108

13. Rowland Hogue CJ, Silver RM. Racial and ethnic disparities in United States: stillbirth rates: trends, risk factors, and research needs. Semin Perinatol (2010) 35(4):221-33. doi:10.1053/j.semperi.2011.02.019

14. Fleming PJ, Blair PS, Ward Platt M, Tripp J, Smith IJ, Group CSR. Sudden infant death syndrome and social deprivation: assessing epidemiological factors after post-matching for deprivation. Paediatr Perinat Epidemiol (2003) 17(3):272-80. doi:10.1046/j.1365-3016.2003.00465.x

15. Mage DT, Donner M. A unifying theory for SIDS. Int J Pediatr (2009) 368270(10):29. doi:10.1155/2009/368270

16. Strandskov HH, Bisaccia $H$. The sex ratio of human stillbirths at each month of uterogestation and at conception. Am J Phys Anthropol (1949) 7(2):131-44. doi:10.1002/ajpa.1330070202

17. Ray JG, Urquia ML. Risk of stillbirth at extremes of birth weight between 20 to 41 weeks gestation. J Perinatol (2012) 32(11):829-36. doi:10.1038/jp.2012.60

18. Blair PS, Fleming PJ, Bensley D, Smith I, Bacon C, Taylor E, et al. Smoking and the sudden infant death syndrome: results from 1993-5 case-control study for confidential inquiry into stillbirths and deaths in infancy. Br Med J (1996) 313(7051):195-8. doi:10.1136/bmj.313.7051.195

19. Morris JA. Common bacterial toxins and physiological vulnerability to sudden infant death: the role of deleterious genetic mutations. FEMS Immunol Med Microbiol (2004) 42(1):42-7. doi:10.1016/j.femsim.2004.06.016 factors for their role in dysregulation of inflammatory responses that could lead to infant death.

\section{Acknowledgments}

The work was funded by the Foundation for the Study of Infant Deaths (FSID) (UK), Babes in Arms (UK), Hunter Medical Research Institute (HMRI), the University of Newcastle, and the Stillbirth Foundation Australia.

20. Blair PS, Ward Platt M, Smith IJ, Fleming PJ. Sudden infant death syndrome and sleeping position in pre-term and low birth weight infants: an opportunity for targeted intervention. Arch Dis Child (2006) 91(2):101-6. doi:10.1136/adc. 2004.070391

21. Chen A, Feresu SA, Fernandez C, Rogan WJ. Maternal obesity and the risk of infant death in the United States. Epidemiology (2009) 20(1):74-81. doi:10.1097/ EDE.0b013e3181878645

22. Johansson S, Villamor E, Altman M, Bonamy AK, Granath F, Cnattingius S. Maternal overweight and obesity in early pregnancy and risk of infant mortality: a population based cohort study in Sweden. BMJ (2014) 349:g6572. doi:10.1136/ bmj.g6572

23. Flenady V, Koopmans L, Middleton P, Frøen JF, Smith GC, Gibbons K, et al. Major risk factors for stillbirth in high-income countries: a systematic review and meta-analysis. Lancet (2011) 377(9774):1331-40. doi:10.1016/ S0140-6736(10)62233-7

24. Aune D, Saugstad O, Henriksen T, Tonstad S. Maternal body mass index and the risk of fetal death, stillbirth, and infant death: a systematic review and meta-analysis. JAMA (2014) 311(15):1536-46. doi:10.1001/jama.2014.2269

25. Stanton C, Lawn JE, Rahman H, Wilczynska-Ketende K, Hill K. Stillbirth rates: delivering estimates in 190 countries. Lancet (2006) 367(9521):1487-94. doi:10. 1016/S0140-6736(06)68586-3

26. Gibbs RS. The origins of stillbirth: infectious diseases. Semin Perinatol (2002) 26(1):75-8. doi:10.1053/sper.2002.29839

27. Quinn PA, Butany J, Chipman M, Taylor J, Hannah W. A prospective study of microbial infection in stillbirths and early neonatal death. Am J Obstet Gynecol (1985) 151(2):238-49. doi:10.1016/0002-9378(85)90020-1

28. Iwasenko JM, Howard J, Arbuckle S, Graf N, Hall B, Craig ME, et al. Human cytomegalovirus infection is detected frequently in stillbirths and is associated with fetal thrombotic vasculopathy. J Infect Dis (2011) 203(11):1526-33. doi:10. 1093/infdis/jir121

29. Gencay M, Koskiniemi M, ÄMmÄLÄ P, Fellman V, NÄRvÄNen ALE, WahlstrÖM T, et al. Chlamydia trachomatis seropositivity is associated both with stillbirth and preterm delivery. APMIS (2000) 108(9):584-8. doi:10.1034/ j.1600-0463.2000.d01-101.x

30. Tolfvenstam T, Papadogiannakis N, Norbeck O, Petersson K, Broliden K. Frequency of human parvovirus B19 infection in intrauterine fetal death. Lancet (2001) 357(9267):1494-7. doi:10.1016/S0140-6736(00)04647-X

31. Blackwell CC, Gordon AE, James VS, MacKenzie DA, Mogensen-Buchanan $\mathrm{M}$, El Ahmer OR, et al. The role of bacterial toxins in sudden infant death syndrome (SIDS). Int J Med Microbiol (2002) 291(6-7):561-70. doi:10.1078/ 1438-4221-00168

32. Bettelheim KA, Goldwater PN, Evangelidis H, Pearce JL, Smith DL. Distribution of toxigenic Escherichia coli serotypes in the intestines of infants. Comp Immunol Microbiol Infect Dis (1992) 15(1):65-70. doi:10.1016/0147-9571(92)90103-X

33. Van Bodegom D, May L, Meij HJ, Westendorp RGJ. Regulation of human life histories. Ann N Y Acad Sci (2007) 1100(1):84-97. doi:10.1196/annals.1395.007

34. Ibiebele I, Coory M, Boyle FM, Humphrey M, Vlack S, Flenady V. Stillbirth rates among indigenous and non-indigenous women in Queensland, Australia: is the gap closing? BJOG (2014). doi:10.1111/1471-0528.13047

35. Hoffmann SC, Stanley EM, Cox ED, DiMercurio BS, Koziol DE, Harlan DM, et al. Ethnicity greatly influences cytokine gene polymorphism distribution. Am J Transplant (2002) 2(6):560-7. doi:10.1034/j.1600-6143.2002.20611.x

36. Ness RB, Haggerty CL, Harger G, Ferrell R. Differential distribution of allelic variants in cytokine genes among African Americans and white Americans. Am J Epidemiol (2004) 160(11):1033-8. doi:10.1093/aje/kwh325 
37. Moscovis SM, Gordon AE, Al Madani OM, Gleeson M, Scott RJ, RobertsThomson J, et al. Interluekin-10 and sudden infant death syndrome. FEMS Immunol Med Microbiol (2004) 42:130-8. doi:10.1016/j.femsim.2004.06.005

38. Moscovis SM, Gordon AE, Al Madani OM, Gleeson M, Scott RJ, RobertsThomson J, et al. Interleukin-1b and sudden infant death syndrome. FEMS Immunol Med Microbiol (2004) 42:139-45. doi:10.1016/j.femsim.2004.06.005

39. Moscovis SM, Gordon AE, Al Madani OM, Gleeson M, Scott RJ, RobertsThomson J, et al. IL6 G-174C associated with sudden infant death syndrome in Caucasian Australian infants. Hum Immunol (2006) 67:819-25. doi:10.1016/ j.humimm.2006.07.010

40. Cox AJ, Moscovis SM, Blackwell CC, Scott RJ. Cytokine gene polymorphism among indigenous Australians. Innate Immun (2014) 20(4):431-9. doi:10.1177/ 1753425913498911

41. Simhan HN, Krohn MA, Roberts JM, Zeevi A, Caritis SN. Interleukin-6 promoter -174 polymorphism and spontaneous preterm birth. Am J Obstet Gynecol (2003) 189(4):915-8. doi:10.1067/S0002-9378(03)00843-3

42. Goepfert AR, Jeffcoat MK, Andrews WW, Faye-Petersen O, Cliver SP, Goldenberg RL, et al. Periodontal disease and upper genital tract inflammation in early spontaneous preterm birth. Obstet Gynecol (2004) 104(4):777-83. doi:10.1097/ 01.AOG.0000139836.47777.6d

43. Velez D, Fortunato S, Morgan N, Edwards T, Lombardi S, Williams S, et al. Patterns of cytokine profiles differ with pregnancy outcome and ethnicity. Hum Reprod (2008) 23(8):1902-9. doi:10.1093/humrep/den170

44. Wenstrom KD, Andrews WW, Hauth JC, Goldenberg RL, DuBard MB, Cliver SP. Elevated second-trimester amniotic fluid interleukin-6 levels predict preterm delivery. Am J Obstet Gynecol (1998) 178(3):546-50. doi:10.1016/ S0002-9378(98)70436-3

45. Frøen JF, Arnestad M, Vege Å, Irgens LM, Rognum TO, Saugstad OD, et al. Comparative epidemiology of sudden infant death syndrome and sudden intrauterine unexplained death. Arch Dis Child (2002) 87(2):F118-21. doi:10. 1136/fn.87.2.F118

46. Pinar H, Goldenberg RL, Koch MA, Heim-Hall J, Hawkins HK, Shehata B, et al. Placental findings in singleton stillbirths. Obstet Gynecol (2014) 123(2, Pt 1):325-36. doi:10.1097/AOG.0000000000000100

47. Hulthén Varli I, Kublickas M, Papadogiannakis N, Petersson K. Chorioamnionitis without foetal inflammatory response is associated with stillbirth in early preterm pregnancies. J Matern Fetal Neonatal Med (2013) 26(10):953-9. doi:10.3109/14767058.2013.766706

48. Romero R, Espinoza J, Gonçalves LF, Kusanovic JP, Friel L, Hassan S. The role of inflammation and infection in preterm birth. Semin Reprod Med (2007) 25(01):021-39. doi:10.1055/s-2006-956773

49. Burns C, Hall ST, Smith R, Blackwell C. Cytokine levels in late pregnancy: are female infants better protected against inflammation?. Front Immunol (2015) 6:318. doi:10.3389/fimmu.2015.00318

50. Moscovis S, Hall S, Burns C, Scott R, Blackwell C. Development of an experimental model for assessing the effects of cigarette smoke and virus infections on inflammatory responses to bacterial antigens. Innate Immun (2014) 20(6):647-58. doi:10.1177/1753425913503893

51. Larcombe L, Rempel JD, Dembinski I, Tinckam K, Rigatto C, Nickerson P. Differential cytokine genotype frequencies among Canadian aboriginal and Caucasian populations. Genes Immun (2004) 6(2):140-4. doi:10.1038/sj.gene. 6364157

52. Park J, CW P, Lockwood C, ER N. Role of cytokines in preterm birth ad birth. Minerva Ginecol (2005) 57(4):349-66.

53. Holst D, Garnier Y. Preterm birth and inflammation - the role of genetic polymorphisms. Eur J Obstet Gynecol Reprod Biol (2008) 141(1):3-9. doi:10. 1016/j.ejogrb.2008.07.020

54. Shobokshi A, Shaarawy M. Maternal serum and amniotic fluid cytokines in patients with preterm premature rupture of membranes with and without intrauterine infection. Int J Gynaecol Obstet (2002) 79(3):209-15. doi:10.1016/ S0020-7292(02)00238-2

55. Daher S, Denardi KDAG, Blotta MHSSL, Mamoni RL, Reck APM, Camano $\mathrm{L}$, et al. Cytokines in recurrent pregnancy loss. J Reprod Immunol (2004) 62(1):151-7. doi:10.1016/j.jri.2003.10.004

56. Romero R, Espinoza J, Chaiworapongsa T, Kalache K. Infection and prematurity and the role of preventive strategies. Semin Neonatol (2002) 7(4):259-74. doi:10.1053/siny.2002.0121

57. Haun L, Kwan N, Hollier L. Viral infections in pregnancy. Minerva Ginecol (2007) 59(2):159-74.
58. Lundemose JB, Smith H, Sweet C. Cytokine release from human peripheral blood leucocytes incubated with endotoxin with and without prior infection with influenza virus: relevance to the sudden infant death syndrome. Int J Exp Pathol (1993) 74(3):291-7.

59. Sarawar SR, Blackman MA, Doherty PC. Superantigen shock in mice with an inapparent viral infection. J Infect Dis (1994) 170(5):1189-94. doi:10.1093/ infdis/170.5.1189

60. Blood-Siegfried J, Shelton B. Animal models of sudden unexplained death. FEMS Immunol Med Microbiol (2004) 42(1):34-41. doi:10.1016/j.femsim.2004. 06.009

61. Cardenas I, Mor G, Aldo P, Lang SM, Stabach P, Sharp A, et al. Placental viral infection sensitizes to endotoxin-induced pre-term labor: a double hit hypothesis. Am J Reprod Immunol (2011) 65(2):110-7. doi:10.1111/j.1600-0897.2010. 00908.x

62. Moscovis SM, Hall ST, Burns CJ, Scott RJ, Blackwell CC. The male excess in sudden infant deaths. Innate Immun (2014) 20(1):24-9. doi:10.1177/ 1753425913481071

63. McDonald SP, Maguire GP, Duarte N, Wang XL, Hoy WE. Carotid intimamedia thickness, cardiovascular risk factors and albuminuria in a remote Australian aboriginal community. Atherosclerosis (2004) 177(2):423-31. doi:10. 1016/j.atherosclerosis.2004.08.004

64. Eslick GD, Yan P, Xia HHX, Murray H, Spurrett B, Talley NJ. Foetal intrauterine growth restrictions with Helicobacter pylori infection. Aliment Pharmacol Ther (2002) 16(9):1677-82. doi:10.1046/j.1365-2036.2002.01333.x

65. Sharma A, Ramesh A, Thomas B. Evaluation of plasma C-reactive protein levels in pregnant women with and without periodontal disease: a comparative study. I Indian Soc Periodontol (2009) 13(3):145-9. doi:10.4103/0972-124X.60227

66. El Ahmer OR, Essery SD, Saadi AT, Raza MW, Ogilvie MM, Weir DM, et al. The effect of cigarette smoke on adherence of respiratory pathogens to buccal epithelial cells. FEMS Immunol Med Microbiol (1999) 23(1):27-36. doi:10.1016/ S0928-8244(98)00114-X

67. Murphy SP, Fast LD, Hanna NN, Sharma S. Uterine NK cells mediate inflammation-induced fetal demise in IL-10-null mice. J Immunol (2005) 175(6):4084-90. doi:10.4049/jimmunol.175.6.4084

68. Robertson SA, Skinner RJ, Care AS. Essential role for IL-10 in resistance to lipopolysaccharide-induced preterm labor in mice. J Immunol (2006) 177(7):4888-96. doi:10.4049/jimmunol.177.7.4888

69. Robertson SA, Care AS, Skinner RJ. Interleukin 10 regulates I inflammatory cytokine synthesis to protect against lipopolysaccharide-induced abortion and fetal growth restriction in mice. Biol Reprod (2007) 76(5):738-48. doi:10.1095/ biolreprod.106.056143

70. Kang X, Kim H-J, Ramirez M, Salameh S, Ma X. The septic shock-associated IL-10 -1082 A > G polymorphism mediates allele-specific transcription via poly(ADP-ribose) polymerase 1 in macrophages engulfing apoptotic cells. $J$ Immunol (2010) 184(7):3718-24. doi:10.4049/jimmunol.0903613

71. Turner DM, Williams DM, Sankaran D, Lazarus M, Sinnott PJ, Hutchinson IV. An investigation of polymorphism in the interleukin-10 gene promoter. Eur J Immunogenet (1997) 24(1):1-8. doi:10.1111/j.1365-2370.1997.tb00001.x

72. Makki K, Froguel P, Wolowczuk I. Adipose tissue in obesity-related inflammation and insulin resistance: cells, cytokines, and chemokines. ISRN Inflamm (2013) 22(139239):22. doi:10.1155/2013/139239

73. Fried SK, Bunkin DA, Greenberg AS. Omental and subcutaneous adipose tissues of obese subjects release interleukin-6: depot difference and regulation by glucocorticoid. J Clin Endocrinol Metabol (1998) 83(3):847-50. doi:10.1210/ jcem.83.3.4660

74. Vgontzas AN, Papanicolaou DA, Bixler EO, Kales A, Tyson K, Chrousos GP. Elevation of plasma cytokines in disorders of excessive daytime sleepiness: role of sleep disturbance and obesity. JClin Endocrinol Metabol (1997) 82(5):1313-6. doi:10.1210/jcem.82.5.3950

75. Ford ES. Body mass index, diabetes, and C-reactive protein among U.S. adults. Diabetes Care (1999) 22(12):1971-7. doi:10.2337/diacare.22.12.1971

76. Karin P, Katarina B, Roger B, Alexandra H, Ingela H-V, Marius K, et al. Diagnostic evaluation of intrauterine fetal deaths in Stockholm 1998-99. Acta Obstet Gynecol Scand (2002) 81(4):284-92. doi:10.1034/j.1600-0412.2002. 810402.x

77. Amu S, Hahn-Zoric M, Malik A, Ashraf R, Zaman S, Kjellmer I, et al. Cytokines in the placenta of Pakistani newborns with and without intrauterine growth retardation. Pediatr Res (2006) 59(2):254-8. doi:10.1203/01.pdr.0000196332. $37565.7 \mathrm{~d}$ 
78. Ernst GDS, de Jonge LL, Hofman A, Lindemans J, Russcher H, Steegers EAP, et al. C-reactive protein levels in early pregnancy, fetal growth patterns, and the risk for neonatal complications: the generation R study. Am J Obstet Gynecol (2011) 205(2):.e1-12. doi:10.1016/j.ajog.2011.03.049

79. Rivera DL, Olister SM, Liu X, Thompson JH, Zhang X, Pennline K, et al. Interleukin-10 attenuates experimental fetal growth restriction and demise. FASEB J (1998) 12(2):189-97.

80. Yamamoto-Tabata T, McDonagh S, Chang H-T, Fisher S, Pereira L. Human cytomegalovirus interleukin-10 downregulates metalloproteinase activity and impairs endothelial cell migration and placental cytotrophoblast invasiveness in vitro. J Virol (2004) 78(6):2831-40. doi:10.1128/JVI.78.6. 2831-2840.2004

81. Steckler T, Wang J, Bartol FF, Roy S, Padmanabhan V. Fetal programming: prenatal testosterone treatment causes intrauterine growth retardation, reduces ovarian reserve and increases ovarian follicular recruitment. Endocrinology (2005) 146(7):3185-93. doi:10.1210/en.2004-1444

82. Sir-Petermann T, Maliqueo M, Angel B, Lara HE, Pérez-Bravo F, Recabarren SE. Maternal serum androgens in pregnant women with polycystic ovarian syndrome: possible implications in prenatal androgenization. Hum Reprod (2002) 17(10):2573-9. doi:10.1093/humrep/17.10.2573
83. Sir-Petermann T, Hitchsfeld C, Maliqueo M, Codner E, Echiburú B, Gazitúa R, et al. Birth weight in offspring of mothers with polycystic ovarian syndrome. Hum Reprod (2005) 20(8):2122-6. doi:10.1093/humrep/dei009

84. Carlsen SM, Jacobsen G, Romundstad P. Maternal testosterone levels during pregnancy are associated with offspring size at birth. Eur J Endocrinol (2006) 155(2):365-70. doi:10.1530/eje.1.02200

85. Gitau R, Adams D, Fisk NM, Glover V. Fetal plasma testosterone correlates positively with cortisol. Arch Dis Child Fetal Neonatal Ed (2005) 90(2):F166-9. doi:10.1136/adc.2004.049320

Conflict of Interest Statement: The author declares that the research was conducted in the absence of any commercial or financial relationships that could be construed as a potential conflict of interest.

Copyright (C) 2015 Blackwell. This is an open-access article distributed under the terms of the Creative Commons Attribution License (CC BY). The use, distribution or reproduction in other forums is permitted, provided the original author(s) or licensor are credited and that the original publication in this journal is cited, in accordance with accepted academic practice. No use, distribution or reproduction is permitted which does not comply with these terms. 